Check for updates

Cite this: RSC Adv., 2017, 7, 33285

Received 26th January 2017

Accepted 21st June 2017

DOI: $10.1039 / c 7 r a 01175 j$

rsc.li/rsc-advances

\section{Corrosion resistance and biological properties of a micro-nano structured Ti surface consisting of $\mathrm{TiO}_{2}$ and hydroxyapatite}

\author{
Jingzu Hao, $\dagger^{a}$ Ying Li, $\uparrow^{\mathrm{b}}$ Xiaolin Wang, ${ }^{a}$ Xianlin Zhang, ${ }^{a}$ Baoe Li, (DD *a Haipeng $\mathrm{Li}{ }^{a}$ \\ Linxi Zhou, ${ }^{a}$ Fuxing Yin, ${ }^{\text {*a }}$ Chunyong Liang ${ }^{a}$ and Hongshui Wang ${ }^{a}$
}

\begin{abstract}
A micro-nano structured titanium ( $\mathrm{Ti}$ ) surface consisting of titania $\left(\mathrm{TiO}_{2}\right)$ and hydroxyapatite $(\mathrm{HA})$ was produced by one-step micro-arc oxidation (MAO) to improve the corrosion resistance and biological properties. The corrosion resistance was evaluated in simulated body fluids (SBF) by electrochemical impedance spectroscopy (EIS) and anodic polarisation tests. The biological properties were investigated by in vitro cell co-culture experiments and in vivo experiments. The results showed that a microstructured $\mathrm{TiO}_{2}$ coating loaded with a nanostructured $\mathrm{HA}$ slice could be obtained on the $\mathrm{Ti}$ substrate during the MAO process. The MAO induced composite coating showed an increased resistance value and corrosion potential. It also promoted the cell behaviors (proliferation and spreading) on the Ti surface. After implantation in the rat tibias, the bonding strength between the bone tissues and implant was enhanced. The improved corrosion resistance was attributed to the increased thickness of the oxide layer, and the enhanced biological properties resulted from the micro-nanostructure and HA on the Ti surface. Based on these results, it was concluded that the micro-nano structured Ti surface consisting of $\mathrm{TiO}_{2}$ and $\mathrm{HA}$ prepared by MAO has great potential to be applied in the clinic.
\end{abstract}

\section{Introduction}

It is well known that titanium (Ti) has been used in biomaterials for bone and dental implants for a long time due to its good strength, corrosion resistance, biocompatibility and nontoxicity. It has been reported that the good properties are attributed to the natural oxide $\left(\mathrm{TiO}_{2}\right)$ layer formed on the $\mathrm{Ti}$ surface when exposed to air or oxygenated electrolytes. ${ }^{1}$ However, the oxide layer is very thin, approximately $3-5 \mathrm{~nm}$ in thickness; ${ }^{2}$ when implanted in the body, it may be disrupted at very low shear stresses, even rubbing against soft tissues. Although a new passive film forms in milliseconds from reaction with the local environment, metal ions are released during the process. The dissolution of Ti into the human body not only adversely affects the healing of bone and the surrounding tissues, but also can intensify the release of inflammatory cytokines, and sometimes even lead to acute or chronic inflammation. ${ }^{3}$ In addition, the bioinertness of $\mathrm{Ti}$ is also a wellknown factor to induce the implantation failures of Ti-based implants. When implanted in the body, the fibrous tissue is usually found to separate the Ti implants from natural bone

${ }^{a}$ School of Materials Science and Engineering, Hebei University of Technology, Tianjin 300130, China. E-mail: libaoe@hotmail.com; fordjp@163.com; Fax: +86 22 60204129; Tel: +8618202287097

${ }^{b}$ Stomatological Hospital, Tianjin Medical University, Tianjin 300070, China

$\dagger$ Jingzu Hao and Ying Li contribute to this work equally. tissues, inhibiting their direct connection and raising the potential risk of loosening in the long-term usage. ${ }^{4}$ Therefore, surface modification to increase the thickness of the oxide layer and bioactivity of Ti implant to improve its corrosion resistance and biological properties has become one of the focuses of the biomaterial research at present.

Micro-arc oxidation (MAO) is an economical, simple, and versatile technique to produce oxide layers on a variety of metals and alloys (e.g. alumina, Ti-based alloys). The structure and thickness of the oxide layer can be tailor-made by a careful choice of electrolyte composition and concentration, $\mathrm{pH}$ and applied current density/potential. ${ }^{5}$ Because the oxide layer prepared by MAO are partial conversion of the body material, there is no sharp interface between the substrates and the oxide layer, the bonding strength and stability will be higher than the plasma sprayed $\mathrm{TiO}_{2}$ coatings which is now commercially used in clinic. In addition, during MAO process, bioactive constitutes such as $\mathrm{Ca}$ and $\mathrm{P}$ which are preferred by osteoblasts can also be introduced to the implant surface based on the gradient forces from kinetics and thermodynamics in electrolyte, consequently improve the biological properties of the implant materials. ${ }^{6}$

Till now, many researchers have prepared the $\mathrm{TiO}_{2} /$ hydroxyapatite $\left(\mathrm{HA}, \mathrm{Ca}_{10}\left(\mathrm{PO}_{4}\right)_{6}(\mathrm{OH})_{2}\right)$ coatings on Ti surface by MAO. In their work, HA (the top layer) can bind directly with the human bone due to its composition similar to that of the bone tissues, endowing the $\mathrm{Ti}$ implant with excellent biological properties. And the $\mathrm{TiO}_{2}$ coating, the intermediate layer, can 
effectively inhibit the dissolution of Ti into the human body and reduce the mismatch of linear thermal expansion coefficient and elastic modulus between $\mathrm{HA}$ and $\mathrm{Ti}$ substrate, strongly increasing the adhesion strength. The shortcoming of their $\mathrm{TiO}_{2} / \mathrm{HA}$ coatings is that, the obtained HA coating is not entirely stable in physiological environment, its corrosion resistance is a little poor and has potential to form surface residuals which are harmful to the osteoblasts. ${ }^{7}$ Therefore, the research focus of this work is to improve the stability of the $\mathrm{TiO}_{2} / \mathrm{HA}$ coating prepared on Ti surface through MAO.

In addition, the micro-nano structured implant has recently been attracting more and more attention. It has been suggested that microtopographies can effectively promote bone-toimplant contact via such mechanisms as mechanical interlocking and enhancement of osteoblast functions. Meanwhile, it can also encourage the bone tissue in-growth to ensure the fixation of implants. And the nanometer scale features can significantly improve cell behaviors, such as adhesion, proliferation and differentiation in vitro and in vivo. In our previous work, the micro-nano structured implant has been proved to be a more suitable surface topography for cell functions as it can better mimic the structure of the natural bone tissues which are composed of nano-, micro-, and macro-scale building blocks. ${ }^{8}$ Table 1 summarized the research work on the micro-nano structured Ti implant surface till now. It can be known that, micro-arc oxidation has been combined with hydrothermal treatment to prepare the micro-nano structured $\mathrm{Ca} / \mathrm{P}$ coating on Ti surface, the former introduces microstructure and the latter lead to nanostructure from recrystallization. Nanostructured HA can also be mineralized on the microstructured

Table 1 Summary of the research work done on micro-nanostructured Ti implant surface

Methods used to obtain the micro-

Authors nanostructure on Ti surface

Photolithography and reactive ion etching techniques, combined with mineralization of nano structured HAP Controlling the thermophysical interactions during laser processing Direct growth of nanostructured titanates on microporous Ti-based metal via a facile low temperature hydrothermal treatment

K. Kubo, et al.

(1) L. Gao, et al. (2) L. Zhao, et al. (3) P. Jiang, et al. (4) B. Li, et al. (5) X. Chen, et al. (6) N. Ren, et al., (7) X. Cheng, et al.

$\mathrm{TiO}_{2}$ nanonodule was sputter deposited onto the acid-etched surface Acid etching and anodic oxidation
$\mathrm{TiO}_{2}$ was sputter-deposited onto the acidetched surface

A simple oxidation of sandblasted/acidetched Ti surfaces

$\mathrm{TiO}_{2}$ nanonodule was deposited onto the acid-etched surface using a sputter deposition system

W. Meng, et al.

Y. Han, et al.

W. Zhang, et al.

Y. Xie, et al.

S. Yavari, et al.

W. Yang, et al.

X. Zhang, et al.
Electrolytic Etching (EE)

Micro-arc oxidation and hydrothermal treatment

Recrystallization of the molten powders after plasma spraying

Anodic oxidation of the plasma sprayed micro-scale titanium coating

Selective laser melting and anoid oxidation

Spin-assisted layer-by-layer assembly

technique

Magnetron sputtering, MAO,

hydrothermal
Journals which publish the research work

Biomaterials, 2004, 25, 3593-3601

Mater. Sci. Tech., 2008, 24, 1144-1161

Nano Lett., 2008, 8, 3803-3808

Biomaterials, 2009, 30, 5319-5329

(1) J. Biomed. Mater. Res., Part B: Appl. Biomater., 2009, 89, 335-341. (2)

Biomaterials, 2012, 33, 2629-2641. (3) Appl. Surf. Sci., 2013, 280, 373-380. (4) RSC Adv. , 2015, 5, 49552-49558. (5) Adv. Engineering Mater., 2012, 14, B216-B223. (6) Brit. J. Oral Maxil. Surg., 2014, 52, 907912. (7) Clin. Implant. Dent. R, 2017, 19, 539-548

Dental Materials, 2010, 26, 275-287

Biomaterials, 2011, 32, 3395-3403

Biomaterials, 2011, 32, 4358-4368

(1) J. Bionic. Eng., 2011, 8, 234-241. (2) Implant. Dent., 2013, 22, 656-661 Nanotechnology, 2011, 22, 275603

Biomaterials, 2013, 34, 3184-3195

Mater. Sci. Eng: C, 2014, 38, 272-277

Appl. Surf. Sci., 2014, 290, 287-294

Acta Biomaterialia, 2014, 10, 4525-4536

Mater. Lett., 2017, 193, 97-100 
Ti surface prepared by photolithography and reactive ion etching techniques. Although the good biological properties are both achieved through these methods, their preparation process is a little complex. There is necessity to explore simple method to obtain the micro-nano structured HA coating on $\mathrm{Ti}$ surface.

Therefore, in this study, the preparation of micro-nano structured implant surface consisting of stable $\mathrm{TiO}_{2} / \mathrm{HA}$ coating was explored on Ti surface by one-step MAO. The composite coating is expected to have improved corrosion resistance and biological properties. The corrosion resistance was evaluated by electrochemical impedance spectroscopy (EIS) and anodic polarisation tests in simulated body fluids (SBF). The biological properties of the Ti implant was evaluated by in vitro cell coculture experiment and in vivo experiment.

\section{Materials and methods}

\subsection{Preparation of samples}

Commercially pure Ti (TA1, Tianjin, China) with the dimensions of $10 \mathrm{~mm} \times 10 \mathrm{~mm} \times 1 \mathrm{~mm}$ was used as the substrate material. After polishing with \#1000 SiC sandpaper and ultrasonic cleaning in acetone, ethanol and deionized water, respectively, the substrates were micro-arc oxidized in an electrolyte containing $0.2 \mathrm{~mol} \mathrm{~L}^{-1}$ calcium acetate $\left(\left(\mathrm{CH}_{3^{-}}\right.\right.$ $\left.\mathrm{COO})_{2} \mathrm{Ca} \cdot \mathrm{H}_{2} \mathrm{O}\right)$ and $0.1 \mathrm{~mol} \mathrm{~L}^{-1}$ monosodiumorthophosphate $\left(\mathrm{NaH}_{2} \mathrm{PO}_{4} \cdot 2 \mathrm{H}_{2} \mathrm{O}\right)$ for 3 min using a direct current (DC) power supply. All chemical regents used here are analytically pure and supplied by Tianjin chemical reagent factory, China. The applied voltage, pulse frequency and duty cycle were separately $360 \mathrm{~V}, 100 \mathrm{~Hz}$, and 50\%. The other experimental details were carried out according to the previously described procedures. ${ }^{9}$ After the MAO treatment, the samples were cleaned with distilled water and air dried. And then, surface morphology and crystal structure of the sample surface were separately examined by scanning electron microscopy (SEM, Hitachi S-4800) and X-ray diffraction (XRD, Rigaku D/max 2500). The bonding strength between $\mathrm{TiO}_{2}$ coating and the Ti substrate was tested by a WS-2000 scratch tester according to the ref. 9 .

\subsection{Corrosion resistance evaluation}

The corrosion behavior of the sample surfaces were examined by EIS and anodic polarisation tests in a conventional threeelectrode cell (volume $300 \mathrm{~mL}$ ) at a temperature of $37 \pm$ $1{ }^{\circ}$ C. $^{10}$ The electrochemical measurements started after the samples were immersed in the SBF for $1 \mathrm{~h}$ under open-circuit conditions. The ionic concentrations in SBF are nearly equal to those in human blood plasma. It was prepared by dissolving the analytically pure chemicals (supplied by Sinopharm Chemical Reagent Co., Ltd, China) of $\mathrm{NaCl}, \mathrm{NaHCO}_{3}, \mathrm{KCl}$, $\mathrm{KH}_{2} \mathrm{PO}_{4} \cdot 3 \mathrm{H}_{2} \mathrm{O}, \mathrm{MgCl}_{2} \cdot 6 \mathrm{H}_{2} \mathrm{O}, \mathrm{CaCl}_{2}$, and $\mathrm{Na}_{2} \mathrm{SO}_{4}$ into distilled water and buffered at $\mathrm{pH} 7.4$ at $36.5^{\circ} \mathrm{C}$ with $45 \mathrm{mM}$ trimethanol aminomethane $\left(\left(\mathrm{CH}_{2} \mathrm{OH}\right)_{3} \mathrm{C}\left(\mathrm{NH}_{2}\right)\right)$ and $1 \mathrm{M} \mathrm{HCl.}{ }^{11}$

For anodic polarisation tests, the potential scan started with a potential that was $500 \mathrm{mV}$ more cathodic than an open-circuit potential, which then increased towards the anodic values at a constant rate of $10 \mathrm{mV} \mathrm{s}^{-1}$ and stopped when the breakdown potential $\left(E_{\mathrm{br}}\right)$ was achieved. For EIS measurements, the electrochemical workstation (HZ-5000 series, China) was used. The frequency ranged from $1000 \mathrm{kHz}$ to $10 \mathrm{mHz}$ at an ac voltage of $\pm 10 \mathrm{mV}$. Impedances were measured at the open circuit potential for all samples. EIS results were analysed using the complex non-linear least-square immittance fitting program LEVM version 7.1 of MacDonald.

\subsection{Biological properties evaluation}

2.3.1 In vitro cell co-culture experiments. MC3T3-E1 murine preosteoblasts (supplied by Tianjin Medical University, China) were seeded on the sample surfaces and co-cultured at $37^{\circ} \mathrm{C}$ for 1,4 and 7 days. During the experimental time, the proliferation rate of the osteoblasts on the sample surfaces was evaluated and compared by the MTT (Sigma, MO) colorimetric assay. ${ }^{12}$ And the cell morphologies were observed by SEM. The experimental details can be seen in our previous work. ${ }^{\mathbf{1 3}}$

2.3.2 In vivo experiments. This study was carried out in strict accordance with the recommendations in the Guide for the Care and Use of Laboratory Animals of the National Institutes of Health. The ethical and methodological aspects of the investigation were approved by Animal Ethical and Welfare Committee (AEWC) of Tianjin Medical University (approval no. TMUaMEC 2016006). 16 week-old male Sprague Dawley rats $(450 \pm 10 \mathrm{~g})$ were obtained from Model Animal Center of Radiological Medicine Research Institute, Chinese Academy of Medical Science (license no. SCXK Tianjin 20140001).

Rats were randomized into Ti group and MAO treated group $(n=5)$. The surgery was conducted under general anesthesia induced by intraperitoneal administration of sodium pentobarbital (50 mg per $\mathrm{kg}$ body weight). The cylindrical implant rods in diameter of $2 \mathrm{~mm}$ were separately implanted into the femora of healthy adult rats. One implant in each femur, and each rat had two implants inserted. After implantation for 5 weeks, rats were sacrificed using an overdose of sodium pentobarbital. The femora containing cylindrical implants were harvested. Then, the biomechanical push-out test was used to assess the bonding strength between bone tissues and implant material, and the interface between bone tissues and implants was observed by SEM. The experimental details can refer to ref. 14. The chemical regents used during in vitro and in vivo experiments were all analytical grade reagents purchased from American companies (Gibco BRL, Logan, Sigma) and Sangon Biotech Co., Ltd. China.

\subsection{Statistical analysis}

Samples were run in quintuplicate for each group. Standard deviations were plotted as error bars for the data points on all figures. For the majority of the data, the experimental error was found to be reasonable. Statistically difference was determined by Students $t$-test. Difference with $p<0.05$ was considered to be significant. 

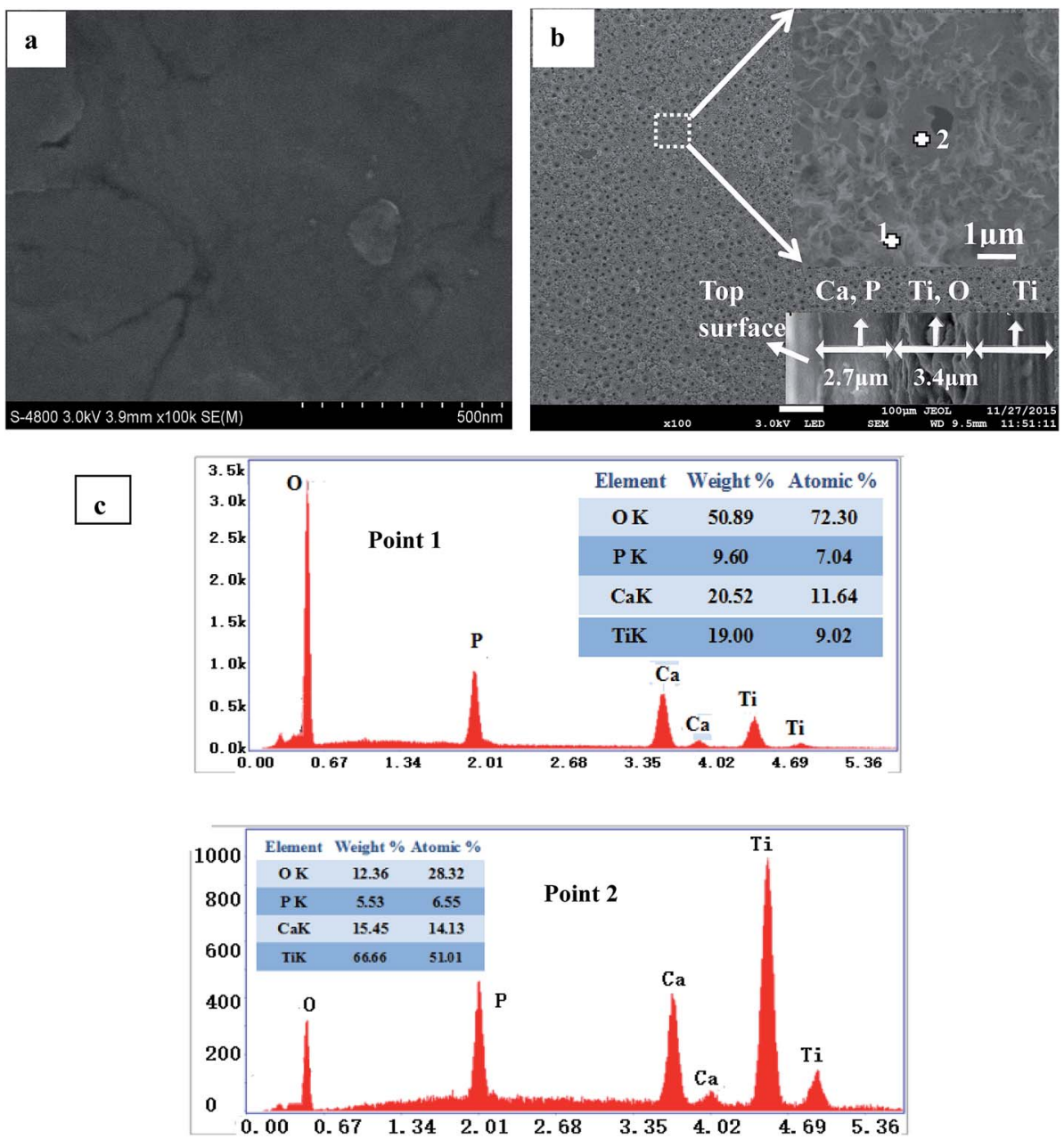

Fig. 1 Surface morphologies of the Ti samples before (a) and after (b) MAO treatment, and the EDS results of two points in MAO treated Ti surface (c).

\section{Results and discussion}

Fig. 1 presented the surface morphologies of the Ti samples before and after MAO treatment. Without surface treatment, the polished Ti samples showed an even and smooth surface (Fig. 1a). After MAO treatment, a composite coating consisting of porous structure and plate-like structure was produced on $\mathrm{Ti}$ surface (Fig. 1b), and the plate-like structured substance was uniformly located around the pores of the porous structure. The pore density determined by the image processing software was about $11 \%$. The diameter of the pores was around $1 \mu \mathrm{m}$, and the plate-like structured substance was about $100 \mathrm{~nm}$ in width and $2 \mu \mathrm{m}$ in length. The plate-like structured substance also clustered to form some nanostructures. The SEM images confirmed the establishment of a hybrid micro-nanostructure on $\mathrm{Ti}$ surface by MAO. The cross-sectional morphology (inserted in bottom right of Fig. 1b) showed that the composite coating had a two-layer structure - a dense inner layer and a porous outer layer. The latter contains microscopic pores, whereas the inner layer is relatively compact. The average thicknesses of the outer layer and inner layer were approximately 2.7 and $3.4 \mu \mathrm{m}$, respectively. EDS analysis of the two layers (Fig. 1c) revealed that the outer layer composed of slice substance was rich in $\mathrm{Ca}$ and $\mathrm{P}$ elements, and the $\mathrm{Ca} / \mathrm{P}$ ratio is about 1.65 (point 2 in Fig. 1b), similar to that of the pure HA. While compared with the EDS results of the outer layer, the inner layer was rich in $\mathrm{Ti}$ and $\mathrm{O}$ elements (point 1 in Fig. 1b). Extending the depth toward the substrate, only the element of Ti was detected. The EDS analysis results obtained from the cross section (not shown here) were in good agreement with the EDS results from the surface points.

Fig. 2 showed the XRD patterns of the Ti samples before and after MAO treatment. It can be seen that, only the typical peaks of Ti were observed on the untreated Ti surface, while for the MAO treated Ti, the crystalline phases of $\mathrm{HA}$ and $\mathrm{TiO}_{2}$ were all obtained. Combined with the EDS results shown in Fig. 1, it can be concluded that the porous structure on the MAO treated $\mathrm{Ti}$ surface was mainly built up by $\mathrm{TiO}_{2}$, and the plate-like structure was formed by HA slice. It is worthy to note that, compared with the other MAO modified Ti surface shown in reference, the $\mathrm{TiO}_{2} / \mathrm{HA}$ coating obtained in this work remained not only the micropores of $\mathrm{TiO}_{2}$ coating but also the nanostructure of HA slice, endowing the Ti surface with micro-nanostructure. The 
formation of micro-nanostructure in this work is due to the low content of $\mathrm{HA}$ introduced to the $\mathrm{TiO}_{2}$ coating, while in the reference, the HA content is usually high enough to totally cover the characters of $\mathrm{TiO}_{2}$ coating.

The formation mechanism of the $\mathrm{TiO}_{2} / \mathrm{HA}$ composite coating during MAO treatment has been reported extensively in previous work. ${ }^{9}$ Generally, when the voltage is greater than the dielectric breakdown voltage of the oxide film, the weakened areas of the oxidation layer will be broken down for the intense micro-arc discharge. Some melted material will spray out from the discharge channel and solidify by the surrounding solution. Ultimately, volcano-like pores form around the discharge channel, forming a porous surface structure. The temperature in areas of glow discharge may reach as high as $2000^{\circ} \mathrm{C}$, which leads to local evaporation of the electrolyte and crystallization of its constituents, and next, to their incorporation in the oxide layer because of the concentration gradient. The $\mathrm{Ca}$ and phosphate ions contained in the solution penetrate the inside of the porous oxide layer, providing a compositional basis for the formation of HA, primary inorganic phases of hard tissues, and has the osteoinductive properties in physiological fluids. The process of HA formation can be described by the following equations.

$$
\begin{gathered}
\mathrm{Ti}(\mathrm{OH})^{3+}+\mathrm{H}_{2} \mathrm{PO}_{4}{ }^{-} \rightarrow \mathrm{Ti}^{4+} \mathrm{HPO}_{4}{ }^{2-}+\mathrm{H}_{2} \mathrm{O} \\
\mathrm{Ti}^{4+} \mathrm{HPO}_{4}{ }^{2-}+\mathrm{OH}^{-} \rightarrow \mathrm{Ti}^{4+} \mathrm{PO}_{4}{ }^{3-}+\mathrm{H}_{2} \mathrm{O} \\
10 \mathrm{Ca}^{2+}+6 \mathrm{HPO}_{4}{ }^{2-}+8 \mathrm{OH}^{-} \rightarrow \mathrm{Ca}_{10}\left(\mathrm{PO}_{4}\right)_{6}(\mathrm{OH})_{2}+6 \mathrm{H}_{2} \mathrm{O} \\
10 \mathrm{Ca}^{2+}+6 \mathrm{PO}_{4}{ }^{3-}+2 \mathrm{OH}^{-} \rightarrow \mathrm{Ca}_{10}\left(\mathrm{PO}_{4}\right)_{6}(\mathrm{OH})_{2}
\end{gathered}
$$

Based on the above description of MAO process, the strong bonding strength can be expected due to the high reaction temperature. Evaluated by scratch testing, the bonding strength between MAO induced $\mathrm{TiO}_{2}$ coating and Ti substrate was found to be about $48 \mathrm{~N}$. However, the bonding strength between HA and $\mathrm{TiO}_{2}$ coating has a great range, which may be due to that the HA content is a little less and the HA slice formed dispersedly on the $\mathrm{TiO}_{2}$ coating (shown in Fig. 1b). When the HA content is above an extend, the exact bonding strength (about $26 \mathrm{~N}$ ) can be obtained, which has been reported in our previous work. ${ }^{9}$ To evaluate the bonding strength between $\mathrm{HA}$ and $\mathrm{TiO}_{2}$ coating in this work, the samples were ultrasonic cleaned at $120 \mathrm{~W}$ for several seconds, and then it was found that there is no obvious change in surface morphology, indicating that the HA bonded tightly on the $\mathrm{TiO}_{2}$ coating. It has been well known that the thick coating can lower the interfacial strength and increase the susceptibility to delamination, the bonding strength of the HA coating obtained in this work should be stronger than $26 \mathrm{~N}$ due to its limited content and thickness (Fig. 1b).

The formation of $\mathrm{TiO}_{2}$ and HA has influence on the corrosion resistance of Ti surface. $E_{\text {corr }}$ represents the open circuit potential of a corresponding material. In general, the more electropositive of the $E_{\text {corr }}$, the nobler the corroding material is. Fig. 3a showed the polarization curves of the Ti samples before and after MAO treatment. It can be seen that, compared with the untreated Ti surface, the MAO treated Ti samples showed a shift of the $E_{\text {corr }}$ in the positive direction. It has been reported that the $E_{\text {corr }}$ of pure Ti is about $-0.3 \mathrm{~V}, E_{\text {corr }}$ of $\mathrm{TiO}_{2}$ is about $0.2-0.4 \mathrm{~V}$, and the $\mathrm{HA}$ is about $-0.46 \mathrm{~V}^{15,16}$ During $\mathrm{MAO}, \mathrm{TiO}_{2}$ layer was formed on the surface of Ti substrate, guaranteeing the more inert metal surface and the better corrosion resistance. The negative influence of HA on corrosion resistance was negligible in this work, which may be due to the small amount on Ti surface. The EIS measurements (Fig. 3b) revealed that the MAO treated Ti samples possessed greater corrosion resistance than the untreated Ti surface. The EIS results are in good agreement with the polarization curve. The cross-sectional morphology shown in Fig. 1b has proved that the MAO induced composite coating consisted of a barrier layer and a porous layer on Ti surface. The influence of the two layer structure of the Ti-based implants on corrosion resistance has been well studied in the literature based on equivalent circuit model, and has been proved that they are beneficial to prevent the ions attack in electrolyte, and thereby greatly improve the corrosion resistance of the Ti-based implant materials. ${ }^{17,18}$ Therefore, the positive influence of MAO treatment on corrosion resistance of Ti surface was not explained in detail here.

The cell proliferation on the MAO treated Ti surface was shown in Fig. 4a. It can be seen that, over the 7 day period, the cells showed a time dependent growth pattern on the samples. Compared with the untreated Ti surface, a statistically significant difference $(p<0.05)$ in proliferation was seen. The cell number on MAO treated Ti was much more than that on the untreated Ti surfaces. Fig. $4 \mathrm{~b}$ and $\mathrm{c}$ showed the corresponding cell morphologies on the two kinds of Ti surfaces after culturing for 4 days. It turned out that cells on the untreated surface exhibited a spindle-like morphology with few filopodia, whereas those on MAO treated Ti surface exhibited a polygonal shape with many filopodia extending in all directions and the cells showed a more complete spreading as compared to those on the untreated Ti surface. After implantation in the rat femora for 5 weeks, the MAO treated Ti exhibited a bonding strength of about $80 \mathrm{~N}$ with bone tissues, and the untreated Ti showed

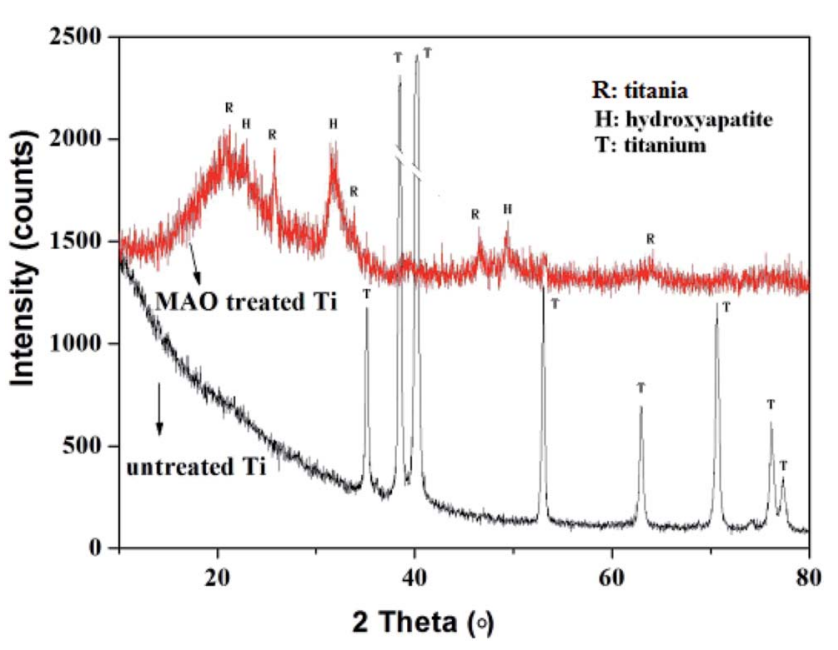

Fig. 2 XRD patterns of the Ti samples before and after MAO treatment. 

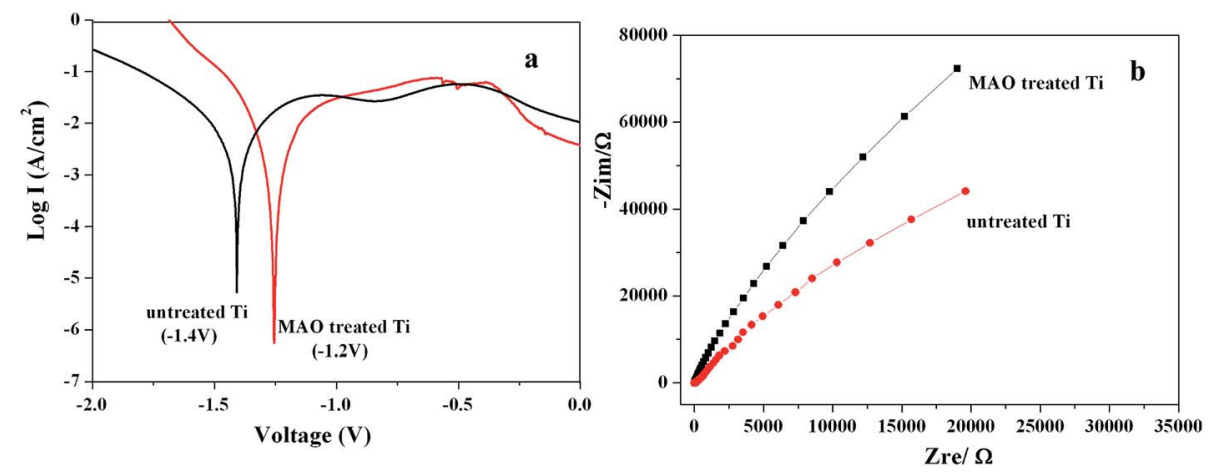

Fig. 3 Polarization curves (a) and EIS spectra (b) of the Ti samples before and after MAO treatment.

a bonding strength of about $39 \mathrm{~N}$ (the push-out test curves were not shown here). It can be concluded that the binding capacity between Ti implant and bone tissue was elevated by the MAO treatment. Fig. 4d showed the interface between the MAO treated $\mathrm{Ti}$ and bone tissues. It can be seen that, the bone tissue is in contact directly with the implant, and the newly formed bone around the implant can not be discriminated from the pre-existing bone, while for the surface untreated Ti implant, the gap between the samples and bone tissues can clearly be seen (interface image was not shown here). The results from in vitro cell culture test and in vivo experiments revealed that the MAO treated Ti promoted cell proliferation, spreading and osteointegration, indicating its better biological properties.

The improved biological properties were attributed to the formation of HA and the micro-nanostructure. Sul et al. ${ }^{19}$ pointed out that the incorporation of $\mathrm{Ca}$ and $\mathrm{P}$ on implant surface can form biochemical bonding between bone/implant, and the bone to metal contact could increase $272 \%$ in $\mathrm{Ca}$ doped implants and $232 \%$ in P doped implants compared to the control groups. Now the commercially used implant material in clinic is HA coated Ti by plasma spray. However, the plasma sprayed HA coating has potential to form surface residuals which are harmful to the osteoblasts, ${ }^{7}$ and the fabrication process is usually time consuming and costly. Accordingly, in this work, low content of HA slice was coupled on Ti surface by $\mathrm{MAO}$, and the HA coating was stable during ultrasonic cleaning, indicating that the obtained HA coating is promising to be applied in clinic. In addition, the positive effect of biomimetic micro-nanostructure on cell behaviours has been extensively reported in recent years. Although the mechanism of the positive effects of micro-nanostructure on biological properties was not very clear, it has been proved that the micro-nanostructure
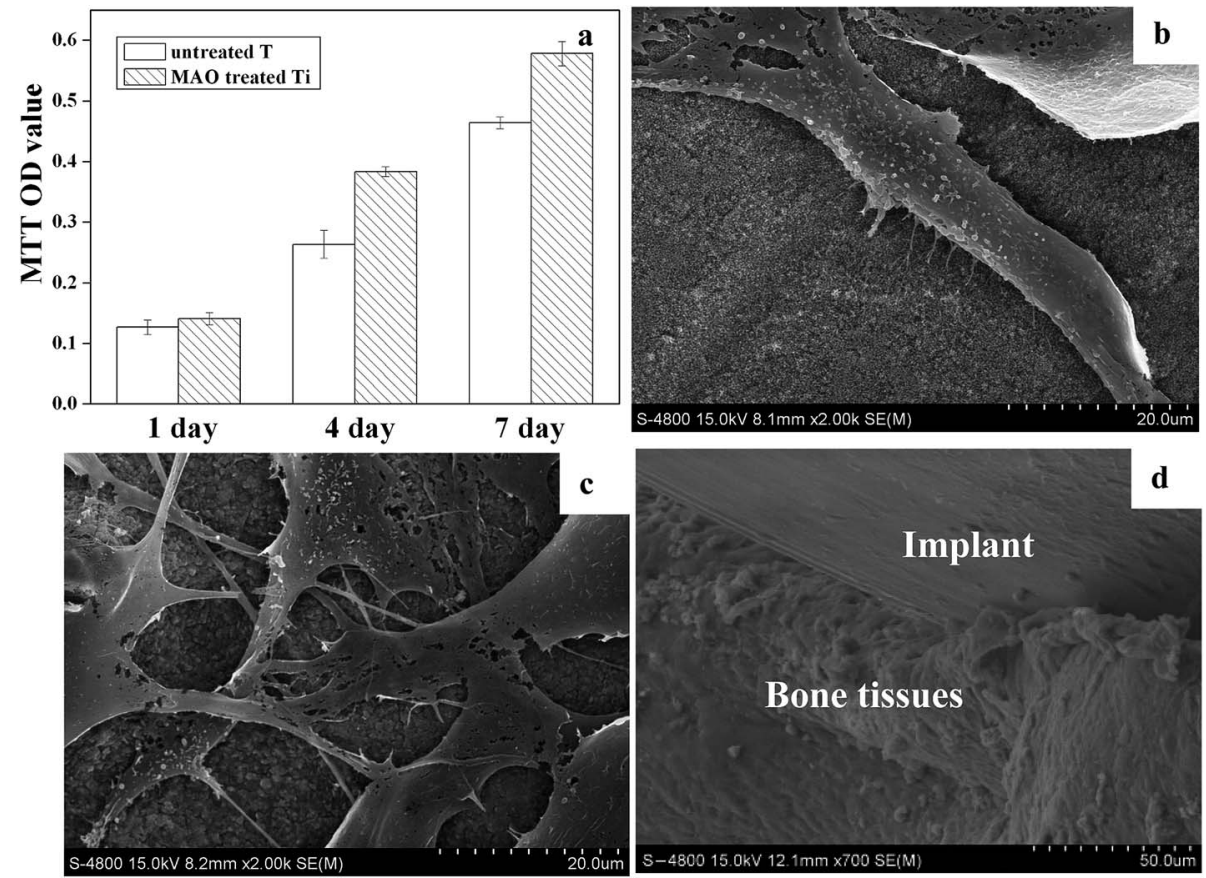

Fig. 4 MTT assay representing the MC3T3-E1 cell proliferation (a) and corresponding cell morphologies on the untreated (b) and MAO treated (c) Ti surfaces, interface between bone tissues and MAO treated Ti (d). 
has the optimal biological properties when compared with micro-scale or nano-scale surface structures. ${ }^{8}$ In this work, the micro-nano structured Ti surface consisting of $\mathrm{TiO}_{2}$ and HA was achieved with simple operation and high efficiency, showing improved corrosion resistance and biological property, which indicates the great potential to be applied in clinic. In addition, in this work, although the optimum diameters of the micro-nanostructure were not presented, however, the porous surface also provides a possibility to develop sustained release system. Drugs and proteins might be anchored in the porous rough surface to further improve the properties of Ti implant materials.

In our future work, more studies will be done on the micronano structured $\mathrm{Ti}$ surface loading $\mathrm{TiO}_{2}$ and $\mathrm{HA}$ to have the optimum corrosion resistance and biological properties, and antibiotics will also be loaded into the micro-scale and nanoscale pores on Ti surface to develop a sustained drug release system, which will endow the Ti-based implant with good antibacterial property.

\section{Conclusions}

In this paper, one-step MAO was applied to modify Ti surface to obtain a micro-nano structured Ti surface consisting of $\mathrm{TiO}_{2}$ and $\mathrm{HA}$. The formation of $\mathrm{TiO}_{2}$ led to the improvement of corrosion resistance. And the micro-nano structured surface as well as the loaded HA resulted in excellent biological properties. Based on these results, it can be concluded that MAO might be a promising method to enhance the performance of Ti-based implants.

\section{Acknowledgements}

The authors gratefully acknowledge the support by the National Natural Science Foundation of China (Project No. 51201056 and No. 81500886), Technology Foundation for returned overseas Chinese scholars (No. C2015003038), Natural Science Foundation of Hebei Province of China (Project No. E2013202021, No. E2017202032), Outstanding Youth Foundation of Hebei Province of China (Project No. E2015202282), Tianjin Natural Science Foundation (No. 16JCYBJC28700) and Science and Technology Correspondent Project of Tianjin (No. 14JCTPJC00496).

\section{References}

1 A. Krząakała, K. Służalska, G. Dercz, A. Maciej, A. Kazek, J. Szade, A. Winiarski, M. Dudek, J. Michalska, G. Tylko, A. M. Osyczka and W. Simka, Characterisation of bioactive films on Ti-6Al-4V alloy, Electrochim. Acta, 2013, 104, 425438.

2 I. S. Park, T. G. Woo, W. Y. Jeon, H. H. Park, M. H. Lee, T. S. Bae and K. W. Seol, Surface characteristics of titanium anodized in the four different types of electrolyte, Electrochim. Acta, 2007, 53, 863-870.

3 M. C. García-Alonso, L. Saldaña, G. Vallés, J. L. GonzálezCarrasco, J. González-Cabrero, M. E. Martínez, E. Gil-Garay and L. Munuera, In vitro corrosion behaviour and osteoblast response of thermally oxidised Ti6Al4V alloy, Biomaterials, 2003, 24, 19-26.

4 Y. Li, B. Li, X. Fu, J. Li, et al., Anodic oxidation modification improve bioactivity and biocompatibility of titanium implant surface, J. Hard Tissue Biol., 2013, 22, 351-358.

5 I. S. V. Marques, M. F. Alfaro, N. C. Cruz, M. F. Mesquita, C. Takoudis, C. Sukotjo, M. T. Mathew and V. A. R. Barão, Tribocorrosion behavior of biofunctional titanium oxide films produced by micro-arc oxidation: synergism and mechanisms, J. Mech. Behav. Biomed. Mater., 2016, 60, 8-21.

6 F. Muhaffel, G. Cempura, M. Menekse, A. C. Filemonowicz, N. Karaguler and H. Cimenoglu, Characteristics of multilayer coatings synthesized on Ti6Al4V alloy by micro-arc oxidation in silver nitrate added electrolytes, Surf. Coat. Technol., 2016, 308-315.

7 G. Balasundaram, C. Yao and T. J. Webster, $\mathrm{TiO}_{2}$ nanotubes functionalized with regions of bone morphogenetic protein2 increases osteoblast adhesion, J. Biomed. Mater. Res., 2008, 84, 447-453.

8 B. Li, Y. Li, Y. Min, J. Hao, C. Liang, H. Li, G. Wang, S. Liu and H. Wang, Synergistic effects of hierarchical hybrid micro/ nanostructures on the biological properties of titanium orthopaedic implants, RSC Adv., 2015, 5, 49552-49558.

9 S. Liu, B. Li, C. Liang, H. Wang and Z. Qiao, Formation mechanism and adhesive strength of a hydroxyapatite $/ \mathrm{TiO}_{2}$ composite coating on a titanium surface prepared by micro-arc oxidation, Appl. Surf. Sci., 2016, 362, 109-114.

10 I. Milošev, D. Blejan, S. Varvara and L. M. Muresan, Effect of anodic oxidation on the corrosion behavior of Ti-based materials in simulated physiological solution, J. Appl. Electrochem., 2013, 43, 645-658.

11 T. Kokubo, H. Kushitani, S. Sakka, T. Kitsugi and T. Yamamuro, Solutions able to reproduce in vivo surfacestructure changes in bioactive glass-ceramic A-W3, J. Biomed. Mater. Res., 1990, 24, 721-734.

12 D. Gerlier and N. Thomasset, Use of MTT colorimetric assay to measure cell activation, J. Immunol. Methods, 1986, 9, 457463.

13 B. Li, Y. Li, J. Li, X. Fu, et al., Influence of nanostructures on the biological properties of $\mathrm{Ti}$ implants after anodic oxidation, J. Mater. Sci.: Mater. Med., 2014, 25, 199-205.

14 C. Liang, H. Wang, J. Yang, Y. Cai, X. Hu, Y. Yang, B. Li, H. Li, C. Li and X. Yang, Femtosecond laser-induced micropattern and $\mathrm{Ca} / \mathrm{P}$ deposition on $\mathrm{Ti}$ implant surface and its acceleration on early osseointegration, ACS Appl. Mater. Interfaces, 2013, 5, 8179-8186.

15 B. Li, X. Wang, Y. Min, C. Liang, H. Li, L. Guo, S. Liu and $\mathrm{H}$. Wang, Corrosion resistance and mechanical properties of titanium with hierarchical micro-nanostructure, Mater. Lett., 2016, 182, 43-46.

16 D. Sidane, D. Chicot, S. Yala and X. Decoopman, Study of the mechanical behavior and corrosion resistance of hydroxyapatite sol-gel thin coatings on 316L stainless steel pre-coated with titania film, Thin Solid Films, 2015, 593, 71-80. 
17 N. Ibriş and J. C. M. Rosca, EIS study of Ti and its alloys in biological media, J. Electroanal. Chem., 2002, 526, 53-62.

18 S. A. Fadl-allah and Q. Mohsen, Characterization of native and anodic oxide films formed on commercial pure titanium using electrochemical properties and morphology techniques, Appl. Surf. Sci., 2010, 256, 5849-5855.
19 Y. Sul, The significance of the surface properties of oxidized titanium to the bone response: special emphasis on potential biochemical bonding of oxidized titanium implant, Biomaterials, 2003, 24, 3893-3907. 